\title{
On change management for enterprise accounting system: iterative content analysis for success factors
}

\author{
Hamzah Ritchi*, Ade Laide Debora \\ Department of Accounting, Universitas Padjadjaran, Bandung, Indonesia \\ ${ }^{*}$ Corresponding author email: hamzah.ritchi@unpad.ac.id
}

\section{A R T I C L E I N F O}

Article history:

Available online

\section{Keywords:}

Change management; critical success factors; ERP; iteration; content analysis

DOI: https://doi.org/10.20885/jaai.vol24.is $\underline{\text { s2.art5 }}$

\section{A B S T R A C T}

The benefits, challenges, and factors that influence the success and failure in implementing ERP have been extensively studied by the previous researchers. In general, the existing literature focuses on general perspectives in organizational contexts. Not many studies have identified the success factors of change management within ERP implementation. Furthermore, few studies attempted to empirically verify these factors. In addition to information system success theory and change management, this study also employed content analysis on SAP Financial and Controlling module. This study attempted to understand the success factors through data reduction mapping, data display, and verification by employing Miles and Huberman data analysis model. Through three iterations based on 26 selected literatures, the top ten initial indicators and three axially coded indicators were derived to be verified as key success factors for change management in implementing Financial and Controlling SAP. The results of this study are to provide an important input for ERP change management initiatives.

\section{Introduction}

Studies about the successful implementation of Enterprise Resources Planning (ERP) system are multidimensional in nature and hold various perspectives. The use of several ERP integration application packages, such as Oracle, SAP, Microsoft Dynamics, and so on is considered a high-quality investment within business applications in financial and cost accounting, sales and distribution, HR management, raw material management, production planning and computer integrated manufacturing (CIM), supply chain, and customer information (Bowen \& Chen, 2001).

Although ERP is beneficial for user satisfaction and its relations in the management of accounting information systems (Grabski et al., 2011; Spathis \& Ananiadis, 2005), a successful implementation of ERP is indeed a challenge which companies have to face. A study on the value of ERP investments for the period of 2010-2013 showed that the investment value of an ERP project scaled around US\$6.5 million on average within 16.1 months (Panorama Consulting, 2014). Considering the funds allocated to these projects, organizations should then be able to integrate all their business processes, increase productivity and efficiency, as well as satisfy and optimize stakeholders. However, the reality differs. According to The Standish Group study, only $28 \%$ of IT projects achieved their goals. This is what motivates this investigation for the critical success factors (CSF) of ERP implementation.

The previous research varied in regard to the search for critical factors of successfully implementing ERP (Aladwani, 2001; Gargeya \& Brady, 2005). Most of these studies were not empirical data (in the form of surveys or cases) nor secondary data (content analysis on specific companies or surveys) oriented, except Themistocleous et al. (2002) who conducted a survey on 50 respondents. However, they did not frame their research specifically in a situation of finding success factors of ERP implementation.

Change Management is one of the critical success factors which is found quite prominent. Nasution (2010) states that managing change requires human resources who understand the purpose of a change and possess the competence to execute it. Change management is one of the critical success factors for ERP implementation that implements structured and proactive processes in handling individuals who are affected by the change and recommendation tactics, such as assessment of readiness to change, training programs, redesign of tasks, and modification of organizational structures (Grabski et al., 2011).

The role of change management is considerably significant in the implementation of ERP systems particularly in minimizing change resistance that can potentially result in the failure of ERP system implementation (Nasution, 2010). The study of change management generally centers on how appropriate the strategies allow the transition from organizational resistance to organizational acceptance of the use of a system (Al-Nafjan \& AlMudimigh, 2011; Aladwani, 2001; Alballaa \& Al-Mudimigh, 2011; Simatupang et al., 2016). Despite its 
significance, it seems that there is still very limited research that has identified the factors that take into account the aspects of successful change management within ERP implementation. Furthermore, there is a scarcity of the investigations that attempted to prove the validity of these factors in a more empirical manner for change management initiatives.

This study aims at exploring and finding out what factors are instrumental to the success of change management in implementing an ERP and further mapping and verifying the construction of these conceptual factors into a field or case study. This research is divided into several parts. The first part describes the background and formulation of the problem. The second section describes the theoretical background and how the initial factors were identified. The third part describes the verification method through mapping mechanism of the initial factors with the results of semi-structured interviews. The discussion of the verification results is set out in the fourth section. Lastly, the fifth section presents the conclusions and potential discussions of further research.

\section{Literature Review}

\section{Information System Success Theory}

An ERP system is a business management system comprising integrated sets of comprehensive software that can be used, when successfully implemented, to manage and integrate all business processes and functions within an organization (Shehab et al., 2004). Hence, it can be inferred that an ERP system is an information system expected to be a business solution in increasing competitive advantages through integration and improvements of decisionmaking timeliness.

Kanellou and Spathis (2013) revealed several benefits to accounting information and practices in ERP system implementation, including driving the need for real-time information and integrated decision making, producing more accurate reports/statements of accounts, improving services for accounting function, and reducing delays in reporting, as well as building integrated data sources on new accounting practices. They also emphasized on how accountants could be aided in carrying out routine tasks more effectively, as well as given more time to analyze and process business supports.

Several theories were applied as the basis for the search for critical factors in this study. Davis (1989) argues that the perceived usefulness and perceived ease of use determine the individual goals in utilizing the system in accordance with the aims of the system with the service as a mediator of the actual use of the system.

Goodhue and Thompson (1995) sought to explain Task Technology Fit (TTF). They argued that information technology (IT) tended to generate positive impacts on individual performance. Information technology is considered functional if its capabilities are in accordance with the tasks performed by individuals and are measured by eight factors: quality, locatability, authorization, compatibility, ease of use/training, production timeliness, system reliability, and relationship with users.

According to DeLone and McLean's (2003) Information System Success Model, the three dimensions comprising information quality, system quality, and service quality relate to the intention to use, user satisfaction, and net benefits. This relates to the importance of the role of information system users that are driven by the characteristics of the information system itself and producing benefits to be reaped in the future. Users become catalysts in the application of information system $\mathrm{s}$.

\section{Successful ERP Implementation}

The success of an ERP system implementation is determined by many factors. The research findings of Tarhini et al. (2015) showed that there were several important factors in the success of implementing an ERP system in a company. The research found that careful change management ranked fifth in the literature content analysis conducted.

In the context of accounting information systems, the implementation of Financial and Controlling (FiCo) module is the principal focus. FiCo module uses SAP master data which is the key source of information, the provider of transactional data, and those associated with all other SAP modules. The solution offered in the FiCo module employs the concept of Financial Solution Balance External and Internal Needs SAP. The existence of business transactions as the basis to formulate FiCo Module, both Fi (Financial Accounting) and Co (Management Accounting), provides solutions for each level of management as decision makers.

In the Financial Accounting $(\mathrm{Fi})$ module, there is an organizational structure comprising client, chart of accounts, company code, and business area. Meanwhile, in Management Accounting (Co), there are operating concerns, controlling area, company code, profit center, and cost center. Both are integrated by automating each function into FiCo module, including General ledger, Accounts Receivable \& Accounts Payable, Bank Accounting \& Cash Management, Asset Accounting, Fund Management and Controlling. 


\section{Change Management}

Change is a shift from the present situation to the desired state in the future. In organizations, changes can occur in organizational structures, operational standards, human resources, and culture. According to Al-Mudimigh et al. (2001) change management is a set of tools, activities, processes and principles that support employees in understanding the shift from the organization's current to future conditions during the implementations of ERP systems to achieve its organizational goals. Thus, it can be seen that the purpose of change management is to provide business solutions to increase the adaptability of an organization, especially the productivity of members within the environmental changes, through an organized method of managing the impacts of change on the people involved.

Prosci (2014) concludes that the main obstacle in conceptual change is the absence of effective change management. This is explained by lack of commitment, unrealistic scope for change, and overall refusal to change. This applies especially when users, organizations, or business units perceive themselves as victims of change rather than initiators. The feeling of comfort in the preceding situation steers the change process to failure. Sometimes companies often underestimate the need for change management, which results in the decline of initiatives to adopt new technology, hence impedes any development.

In Al-Mudimigh et al. (2001), it was estimated that about $50 \%$ of all ERP projects failed to benefit due to underestimating efforts to manage change. Change management is needed to introduce users to the new system, then reduce resistance to the system and influence attitudes towards change (Kemp \& Low, 2008). 90\% of the companies that implement change management in ERP implementation believed that it held a strong influence on the project success (Foster et al., 2007).

One of the change management approaches is ADKAR approach, abbreviation of Awareness, Desire, Knowledge, Ability, and Reinforcement. These five elements focus on managing change individually, design to help diagnose the barriers and resistance to change in employees, and are equipped with change management tools. This model provides an approach to managing change by building awareness of the need for change, prompting eagerness to support and engage, developing an understanding on how to change, aiding to develop and implement necessary skills, and providing reinforcements in sustaining change (Prosci, 2014).

Based on a systematic literature review, it can be inferred that the role of change management in the implementation of ERP system is crucial. This is reinforced by how successful ERP implementation supported by successful change management is. The contents of some of the literature used were collected and analyzed in the initial formulation of change management success factors.

From the abovementioned literature, the success factors of change management were identified and then linked to the practice of change management carried out in the field objects (i.e., companies). The literature review was focused on tracing various factors in the previous studies in the area of change management in the context of ERP system implementation. Hence, the international journals that raised the topic of change management in ERP system implementation would then be coded and subjected to several stages of iterative coding to obtain the success factors of change management.

\section{Research Method}

Based on the explanatory framework, this study strives to combine conceptual and empirical analysis. The main objective of this research is to identify the critical factors of the successful change management in ERP implementation. The research method employed was qualitative method. The research results provided deeper understanding from the generalizations, or what is also called inductive analysis. Thus, the qualitative research method was chosen, as it is the most appropriate approach in understanding change management, which is dynamic in nature, to find the critical success factors for change management in implementing ERP systems in the research object of companies.

\section{Content Analysis}

To identify the factors of the success of change management, content analysis was employed to conduct axial coding to infer the success factors of change management from the literature in a systematic manner. This method is fundamentally empirically oriented and intended to be exploratory and predictive (Krippendorff, 2018). In the context of this research, content analysis was used as a tool to analyze the literature and provide recommendations that would contribute new knowledge, without intending to direct the reader's opinions as it was only intended to indicate the specific factors related to the results.

Journal publications and conference proceedings were used as the main references. In-depth analysis on change management in ERP implementation was the first literature category. This type of group presented the success factors of company management in two forms, namely tables (points) and paragraphs (descriptions) with 
a total of 16 references. In addition, the second category, with a total of ten references, included journals on change management in general, both in theory, its application in enterprise systems, and information technology.

\section{Factor Identification}

The process of identifying instruments of key success factors of change management in ERP implementation was carried out through three iterations. Each iteration applied inclusion criteria which served to include the identified and relevant factors.

In the first iteration stage, the exploration of change management success factors was based on the criteria of the publications discussing change management that was more representative in reality than in an organizational context. The twenty-six main references were in-depth analyzed with regard to the following inclusion criteria: anything that had relevance in the context of change management. The issues or items surrounding this were tagged and grouped by the journal and publication year.

As a result, 219 items were found which the researchers deemed to have relevance to change management. These findings were then identified and grouped based on the similarity of concepts and purposes of identification. Therefore, the succeeding step was to group them into a more general group abstraction. In the second stage of the iteration (Figure 1), the success factors of change management resulting from the first iteration were grouped based on the publications that discussed the change management in ERP implementation. The idea was to group the 219 identified factors into more general factors reflecting the same dimensions. Accordingly, a number of journal articles that discussed change management factors in depth were drawn and included in Figure 1.

From the second grouping, 34 change management success factors were found. However, these factors were still too broad to be understood by various stakeholders, especially for the need to validate the factor identification model during field studies verification on the research object later. Therefore, the third iteration was carried out to categorize the factors that appear in the journal articles with more detailed analysis of change management in ERP implementation. This analysis was presented in tabular form (points) as the principal factors. This was done to avoid error in grouping the factors verbatim. Every factor that had similarities with the principal factors, either the name of the factor or the explanation from the journal describing the principal factors, was grouped as one factor. The works of Al-Mudimigh et al. (2001), Prosci (2014), Shang and Su (2004) and Tarhini et al. (2015) were used as the basis for the grouping.

In the third stage of the factor grouping process, the modifications were made on the names of the principal factors, but these did not change the meaning and concept of the factors themselves. Thus, the grouping of factors in stage two arrived at 20 factors. Then, the top ten factors ranked based on their frequency of appearance in 26 journals were declared as the critical success factors for change management in ERP system implementation. The list of the critical success factors for change management was not only a comprehensive summary, but also formed as the basis for empirical testing of the successful stages of field interviews. The ten selected success factors of change management in the implementation of the ERP system can be seen in Table 1.

Table 1. Ten Key Success Factors of Change Management in ERP Implementation - Conceptual Phase

\begin{tabular}{|c|c|}
\hline Factor Name & Definition \\
\hline Communication & $\begin{array}{l}\text { Widespread participation by employees in direction and process of change } \\
\text { (Shang \& Su, 2004). }\end{array}$ \\
\hline $\begin{array}{l}\text { Evaluation/analysis were done before and } \\
\text { during implementation }\end{array}$ & Analysis stage prior to and after the implementation (Joshi, 1991). \\
\hline Training or educating & $\begin{array}{l}\text { Tools in installing the working of a new system (theoretically and technically } \\
\text { (Kemp \& Low, 2008). }\end{array}$ \\
\hline Culture & $\begin{array}{l}\text { Culture or value systems in organizations that affect the level of } \\
\text { understanding of information management, application functions, and } \\
\text { acceptance towards the ERP system (Altamony et al., 2016). }\end{array}$ \\
\hline Strategy or planning of change & $\begin{array}{l}\text { A form of identification of tactical aspects prepared to face challenges } \\
\text { (Stapleton \& Rezak, 2004). }\end{array}$ \\
\hline Active and visible executive sponsorship & $\begin{array}{l}\text { Manifestation of support for change by providing consistent attention, } \\
\text { leading, and motivating parties involved (Prosci, 2014). }\end{array}$ \\
\hline $\begin{array}{l}\text { Employees/end-users/front-line } \\
\text { participation }\end{array}$ & $\begin{array}{l}\text { Organizational realization of results in change management; evidence that } \\
\text { employees are willing to cooperate and aware of the need for change (Prosci, } \\
\text { 2014). }\end{array}$ \\
\hline Incentives/reward/award & $\begin{array}{l}\text { Aid in developing the desire to accept and adopt a new system (Alballaa \& } \\
\text { Al-Mudimigh, 2011). }\end{array}$ \\
\hline Support escalation/helpdesk/ information & $\begin{array}{l}\text { Guiding tools; assistance provided to overcome difficulties experienced by } \\
\text { system users in resolving one stage or more (Alballaa \& Al-Mudimigh, 2011). }\end{array}$ \\
\hline $\begin{array}{l}\text { Engagement with and support from } \\
\text { middle-management }\end{array}$ & $\begin{array}{l}\text { The management positioned closest to employees is able to convince them of } \\
\text { the positive impacts of change through intense interaction (Prosci, 2014). }\end{array}$ \\
\hline
\end{tabular}




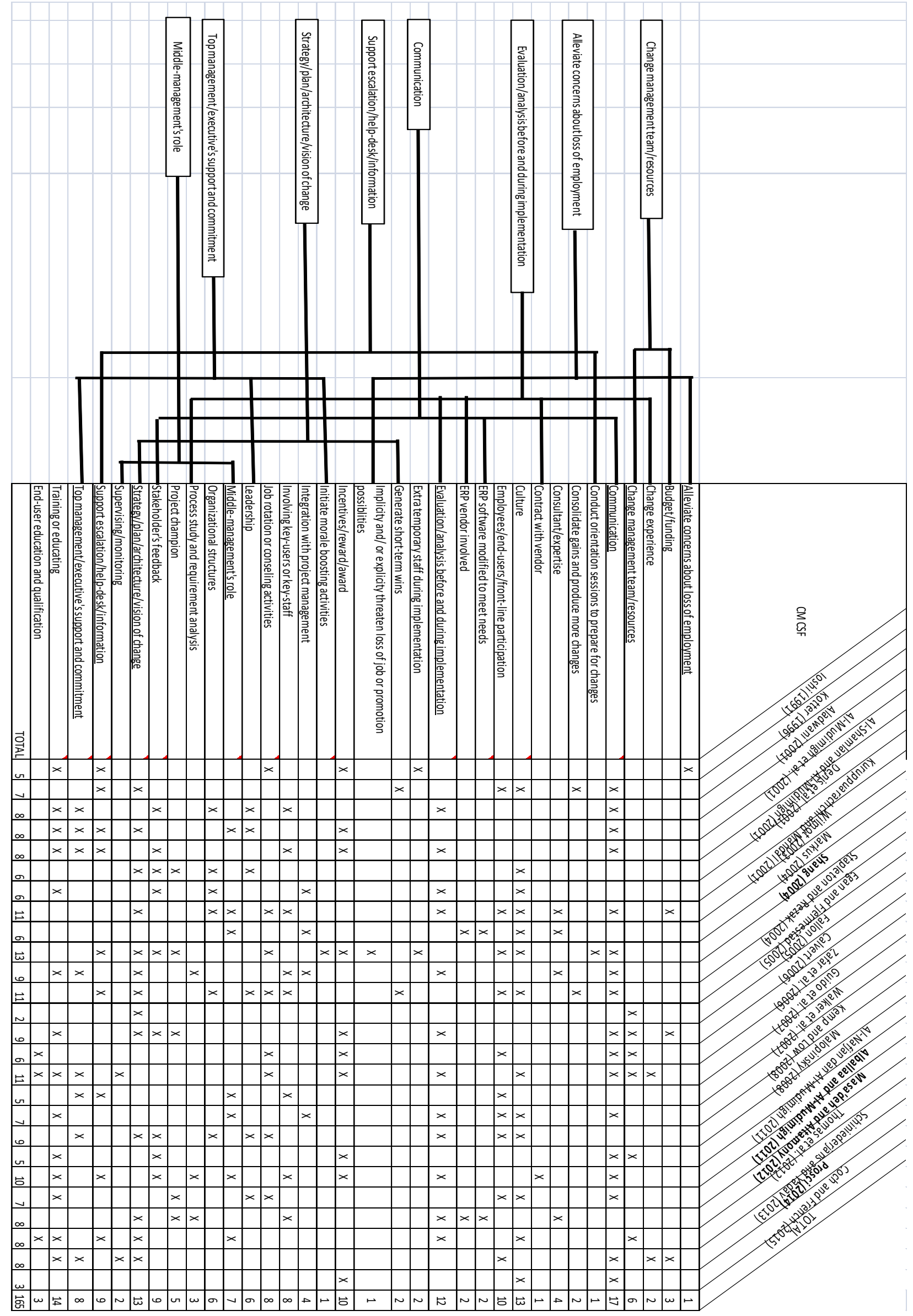

Figure 1. Stage II of Change Management Factors Grouping 


\section{Object and Participants}

To understand how change management works in organizations, the verifications were conducted on an ERP unit supervised by an IT department at the largest airport service company in Indonesia (hereinafter referred to as the Company) which carried out SAP implementation. In this case, the focus of the research was the change management in the implementation of the ERP system Phase 1 - FiCo module.

Based on the characteristics of the informants in qualitative research in Sugiyono (2014), several categories of employees were approached, and the results can be seen in Table 2. The data collection was carried out through semi-structured interviews. The interviews were conducted for approximately 30 minutes per informant. The researcher then transcribed the interview results to carry out the axial codification process using a pre-designed list of factors as the basis. In addition, the documents related to the implementation of change management program in Phase 1 of ERP system implementation from the company's FiCo module and the results of the analysis on the implementation of the company's ERP system were used to support the mapping of the critical success factors for change management.

After that, the data were analyzed using the model of Miles and Huberman (1984) where the activities in the analysis were carried out interactively and lasted until the data was saturated. In the beginning of the process, data reduction was carried out in which the important data were summarized and the patterns were studied. The data were presented in the text form and narrative following the preceding activity. If the data pattern was supported by the research data at this stage, the pattern would be ascertained as standardized and stayed unchanged. This pattern would be presented in the final research report. The final stage was verification in which we drew conclusions in the form of re-mapping the success factors based on the literature and the results of interviews in order to achieve validity.

\section{Results and Discussion}

\section{General Results}

The information on change management in the company's ERP implementation was provided by several informants. The description of the informants can be found in Table 2.

Table 2. Description of Informants

\begin{tabular}{|c|c|c|c|c|c|}
\hline \multicolumn{6}{|c|}{ Main Informants Group } \\
\hline No & Informant Code & Age & Gender & Length of Service & Position in the Implementation \\
\hline 1 & Informant 1 & 34 years & Male & 7 years & $\begin{array}{l}\text { ERP Unit Manager of Change Management } \\
\text { Division of 'Company' }\end{array}$ \\
\hline 2 & Informant 2 & 25 years & Female & 2 years & $\begin{array}{l}\text { ERP Unit Senior Executor (staff) of Change } \\
\text { Management Division of 'Company' }\end{array}$ \\
\hline 3 & Informant 3 & 31 years & Male & 4 years & FiCo module Key User \\
\hline 4 & Informant 4 & 28 years & Male & 4 years & FiCo Module End User \\
\hline \multicolumn{6}{|c|}{ Supporting Informants Group } \\
\hline No & Informant Code & Age & Gender & Length of Service & Position in the Implementation \\
\hline 5 & Informant 5 & 25 years & Male & 2 months & $\begin{array}{l}\text { 'Stage } 2 \text { Consultant', Team Member of FiCo } \\
\text { module consultants }\end{array}$ \\
\hline 6 & Informant 6 & 25 years & Female & 2 months & $\begin{array}{l}\text { 'Stage } 2 \text { Consultant', Project Management } \\
\text { Officer of OCM consultants }\end{array}$ \\
\hline
\end{tabular}

The informants were divided into two groups to identify the changes in the organizational structure in ERP unit, particularly, head of ERP project management and SAP vendor who was also Phase 1 ERP implementation consultant for FiCo module at the time the research was carried out. The group consisting supporting informants was not directly involved in the implementation of ERP phase 1 of FiCo module in 2014 because they had only joined the ERP unit at stage 2.

Subsequently, the indicators of the success factors for change management in the ERP implementation of the "Company" were verified based on the results of semi-structured interviews. Table 3 illustrates the changes of the weight values in the empirical phase of the factor ranks in the conceptual phase. The concept derived from the interview results were mentioned by several informants who stated that those indicators were indeed the critical success factors of change management.

Based on the data reduction, the number of concepts related to the factors that were previously formulated were counted, and their weights were calculated. Table 4 shows the re-weighted indicators based on the interviews. 
The result of the recalculation showed that the first top CSFs in change management relatively remained steady. This gives the message over the importance of those CSFs came from top of executives' mind when commencing the ERP accounting module implementation or migration. It is also worth noting that championship in the form of executive support played the top role for the effectiveness of enterprise-wide Financial and Controlling implementation.

Table 3. Verification of the Ten Key Success Factors of Change Management - Empirical Phase

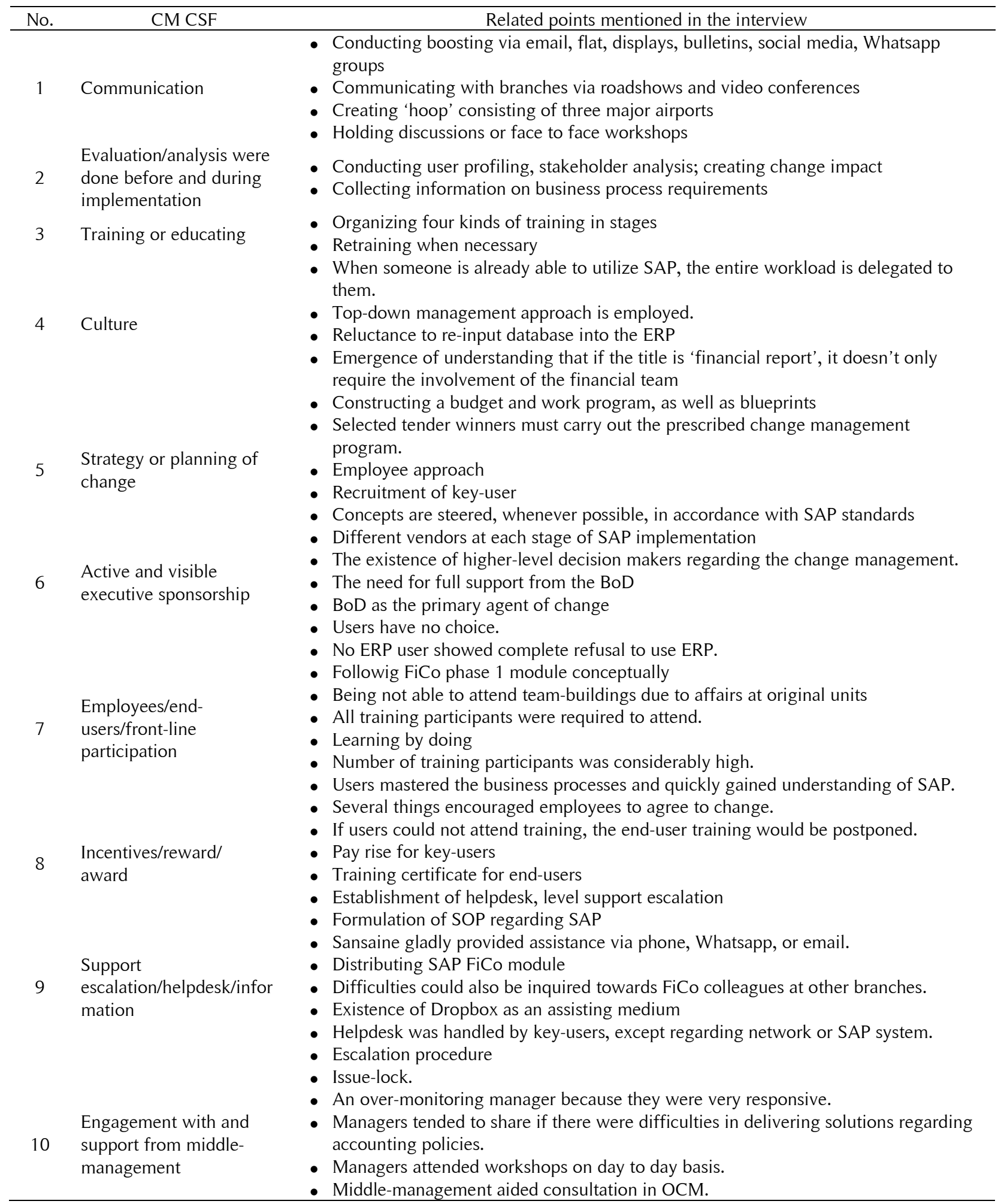


Table 4. Indicator Verification and Findings of Other Indicators

\begin{tabular}{|c|c|c|}
\hline No. & CM CSF & $\begin{array}{l}\text { Informants who mentioned related } \\
\text { points }\end{array}$ \\
\hline 1 & Active and Visible Executive Sponsorship & Informant 1-2-3-4-5 \\
\hline 2 & Communication & Informant $1-2-3-4-5-6$ \\
\hline 3 & Strategy or Planning of Change & Informant $1-2-3-4-5-6$ \\
\hline 4 & Evaluation or analysis done before and during implementation & Informant $1-2-3-4-5-6$ \\
\hline 5 & Training or Educating & Informant $1-2-3-4-5-6$ \\
\hline 6 & Employees/End-user/Front-line Participation & Informant 1-2-3-4-5-6 \\
\hline 7 & Engagement with and Support from Middle-management & Informant 4-6 \\
\hline 8 & Support Escalation/Helpdesk/Information & Informant 1-4-5-6 \\
\hline 9 & Involving key-users or key-staff & Informant 1-2-3-4-5-6 \\
\hline 10 & Culture & Informant 3-4-5-6 \\
\hline 11 & Engagement integration with project management & Informant 3-5-6 \\
\hline 12 & Dedicated change management resources and funding & Informant 1-4 \\
\hline 13 & Incentives/Reward/Award & Informant 3-5 \\
\hline
\end{tabular}

\section{Other Indicators}

Apart from the ten indicators that became the success factors of change management found in the previous literature review, there were other indicators which according to both the main and supporting informants were considered important.

The first is 'dedicated change management resources and funding (rank 12 of CM CSF in Table 4). Change Resources according to Calvert (2006) refer to the financial, human, technological, and capital assets utilized by the change efforts. These resources must be provided in sufficient quantities for a new system implementation to be successful (Altamony et al., 2016). Informant 4 stated that the establishment of a designated unit for ERP implementation was a form of dedication to the success of ERP implementation.

Second, all informants agreed on 'involving key users or key staff' (rank 1 of CM CSF in Table 4) as they all stated that key user contribution as an extension of ERP unit with end users was critical, especially in assisting end users in operating SAP both in terms of knowledge and functionality. Key players participation positively impact the implementation process and the majority of the users stating that the process was successful (Matende et al., 2015). By getting the key players involved from the project inception, they will likely be opened for change and reduce the company's resistance to change (Hasheela-Mufeti \& Smolander, 2017; Mathar \& Gaur, 2020; Ziemba \& Obłąk, 2015).

Lastly, as integration is the main intention of utilizing ERP, it is paramount that integration of the entire project is established in order to avoid clashing between consultants at every stage of SAP implementation. Hence, 'Engagement integration with the project management' (rank 17 of CM CSF in Table 4) is considered another crucial indicator. In his research, Calvert (2006) discovered a relationship between this indicator and the willingness to learn as well as better utilization of the new system, and that this could serve as a kind of internal consultant regarding the system.

The next stage was to determine the indicators according to their level of urgency in the success of change management in the "Company's" ERP implementation, as well as to discuss the indicators that appeared outside the ten factors from the previous iteration of 26 literatures. The changes were not only due to the fact that the factors mentioned by the informants were supported by the existing documentation, but also whether or not contextually in the ERP implementation phase 1 of the FiCo module, these indicators were important in achieving the success of change management in Table 4.

The ninth rank is occupied by the 'Involving Key-user or Key Staff' indicator. In this case, the key-user becomes part of the approach of support after the ERP implementation, or in other words, an internal consultant. The establishment of key-users is expected to become an extension of the ERP unit in operating SAP to end-users in the field.

The 11th rank is occupied by 'Engagement integration with project management'. This is related to the tender system employed in the "Company" which involved different consultants at each stage of the ERP implementation. Great attention was needed in the form of a solid agreement to maintain the sustainability of the project throughout each consultant. This was done to maximize the time and resources available in completing the change management program.

The 12th rank is occupied by 'Dedicated change management resources and funding'. The ERP unit became the bridge between the consultants and internal parties in the "Company". More importantly, the ERP unit was formed as a part of the board of directors' dedication to the success of the ERP project on the grounds that the ERP project was a complex and high-budget project. 
Another study was conducted by Saade and Nijher (2016) who analyzed 37 ERP implementation case studies from different countries and contexts. They found change management dimensions aimed at reducing costs, maintaining timeline, and reducing employee anxieties. Thus, having dedicated resources and funding encompassing communication, active and visible exclusive sponsorship, training, explicit and implicit engagement with project management regarding strategy or planning of change, involving key user or key staff, and culture are expected to bring closer toward the successful ERP-based accounting change.

\section{Conclusion}

This study has attempted to identify the success factors of change management by observing the conceptual aspects as reflected in the studies on change management, particularly in the application of ERP (SAP FiCo). There was a shift between the factors identified through the literature content analysis and the content analysis of the interview results, although they were not substantially different. This provides at least two indications.

First, the selection of the literature and the identified factors met a fairly good degree of validity in explaining the phenomena occurring in the research object 'Company'. Sugiyono (2014) argues that the validity aspect is prioritized in qualitative research rather than the reliability aspect. Some of the procedures used to accommodate this validity included (1) credibility tests through triangulation techniques in which the different data collection techniques were applied to the same exact sources; (2) a reliability test using a semi-structured interview mechanism accompanied by the complementary documentation in which the researcher also examined the responses of the respondents repeatedly; and (3) a confirmatory ability test in which the factors were first assessed and then verified in the social situation of the Company. Thus, the degree of reliability in this study was well preserved, given that the responses of the informants related to the conceptual factors led to the mentioning of the same issue across the informants.

Second, this change management success factor model can be operationalized in the context of implementing SAP FiCo as a reflection of ERP. Furthermore, this model provides a reasonable foundation to help companies identify the success factors beyond the ten previously identified factors. Although it is necessary to apply them to the situation of other companies, at least this identification of the ten factors possesses a higher chance of being applied to other companies' conditions to increase external validity.

Several implications have been detected from two perspectives. First, from the research perspective, this study contributes to scientific literature in the domain of identification of system success factors, in general, and ERP or individual modules, in particular. Second, from the perspective of the Company, this study provides several valuable inputs, including the need to prioritize the preparation of SOPs as an informative guides on SAP; clear work procedures from the Company to each vendor at each stage of ERP implementation so that there is a consistent continuity between the work of the previous vendor and the next one, as well as to minimize repetitive work; and certified training from SAP which can increase interest as well as the quality of the SAP knowledge delivery to SAP users.

Considering that this research still needs the strengthening in external validity, future researchers can administer data collection through questionnaires. The future researchers can also add variables outside of the ten factors that determine the success of change management in ERP implementation, such as approaches or methods used in change management. The informant profile aspect can also be added to the employees who reflect the owner of the system, in this case with regard to the budget, such as directors.

\section{References}

Al-Mudimigh, A. S., Zairi, M., \& Al-Mashari, M. (2001). ERP Software implementation: An integrative framework. European Journal of Information Systems, 10(4), 216-226.

Al-Nafjan, A. N., \& Al-Mudimigh, A. S. (2011). The impact of change management in ERP system: A case study of Madar. Journal of Theoretical and Applied Information Technology, 23(2), 91-97.

Aladwani, A. M. (2001). Change management strategies for successful ERP implementation. Business Process Management Journal, 7(3), 266-275.

Alballaa, H., \& Al-Mudimigh, A. S. (2011). Change management strategies for effective enterprise resource planning systems: A case study of a Saudi company. International Journal of Computer Applications, 17(2), $14-19$.

Altamony, H., Tarhini, A., Zahran Al-Salti, Gharaibeh, A. H., \& Elyas, T. (2016). The relationship between change management strategy and successful enterprise resource planning (ERP) implementations: A theoretical perspective. International Journal of Business Management and Economic Research, 7(4), 690-703.

Bowen, J. T., \& Chen, S. (2001). The relationship between customer loyalty and customer satisfaction. International 
Journal of Contemporary Hospitality Management, 13(5), 213-217.

Calvert, C. (2006). A Change-Management Model for the Implementation and Upgrade of ERP Systems. 17th Australasian Conference on Information Systems, 1-12.

Davis, F. D. (1989). Perceived usefulness, perceived ease of use, and user acceptance of information technology. MIS Quarterly, 13(3), 319-340.

DeLone, W. H., \& McLean, E. R. (2003). The DeLone and McLean model of information systems success: A tenyear update. Journal of Management Information System, 19(4), 3-30.

Foster, S., Hawking, P., \& Zhu, C. (2007). The Human Side of ERP Implementation: Can Change Management Really Make a Difference? In Research and Practical Issues of Enterprise Information Systems II (pp. 239249). Springer.

Gargeya, V. B., \& Brady, C. (2005). Success and failure factors of adopting SAP in ERP system implementation. Business Process Management Jou, 11(5), 501-516.

Goodhue, D. L., \& Thompson, R. L. (1995). Task-technology fit and individual performance. MIS Quarterly, 19(2), 213-236.

Grabski, S. V., Leech, S. A., \& Schmidt, P. J. (2011). A review of ERP research: A future agenda for accounting information systems. Journal of Information Systems, 25(1), 37-78.

Hasheela-Mufeti, V., \& Smolander, K. (2017). What are the requirements of a successful ERP implementation in SMEs? Special focus on Southern Africa. International Journal of Information Systems and Project Management, 5(3), 5-20.

Joshi, K. (1991). A model of users' perspective in change: The case of IS technology implementation. MIS Quarterly, 15(2), 229-242.

Kanellou, A., \& Spathis, C. (2013). Accounting benefits and satisfaction in an ERP environment. International Journal of Accounting Information Systems, 14(3), 209-234.

Kemp, M. J., \& Low, G. (2008). ERP innovation implementation model incorporating change management. Business Process Management Journal, 14(2), 228-242.

Krippendorff, K. (2018). Content Analysis An Introduction to Its Methodology (4th ed.). Sage.

Matende, S., Ogao, P., \& Nabukenya, J. (2015). User participation in ERP implementation: A case-based study. International Journal of Computer Applications Technology and Research, 4(1), 24-29.

Mathar, D., \& Gaur, M. (2020). Change management: Identifying change agents using social network analysis in an ERP implementation. International Journal of Computer Engineering \& Technology, 11(1), 1-9.

Miles, M. B., \& Huberman, A. M. (1984). Drawing valid meaning from qualitative data: Toward a shared craft. Educational Researcher, 13(5), 20-30.

Nasution, M. N. (2010). Manajemen Perubahan. Ghalia Indonesia.

Panorama Consulting. (2014). The 2014 ERP Report: Organizational Change Management. https://cdn2.hubspot.net/hubfs/4439340/2014-ERP-Report-OCM.pdf

Prosci. (2014). Best Practices in Change Management. Prosci Ink. https://www.prosci.com/resources/articles/change-management-best-practices

Saade, R. G., \& Nijher, H. (2016). Critical success factors in enterprise resource planning implementation: A review of case studies. Journal of Enterprise Information Management, 29(1), 72-96. https://doi.org/https://doi.org/10.1108/JEIM-03-2014-0028

Shang, S. S. C., \& Su, T. (2004). Managing User Resistance in Enterprise Systems Implementation. 10th Americas Conference on Information Systems, 146-153.

Shehab, E. M., Shar, M. W., Supramaniam, L., \& Spedding, T. A. (2004). Enterprise resource planning: An integrative review. Business Process Management Journal10, 104), 359-386.

Simatupang, T., Govindaraju, R., \& Amaranti, R. (2016). Change Change management perspectives in an ERP module implementation: A case study in a telecommunication company. Jurnal Teknik Industri, 18(1), 5162. https://doi.org/10.9744/jti.18.1.51-62 
Spathis, C., \& Ananiadis, J. (2005). Assessing the benefits of using an enterprise system in accounting information and management. Journal of Enterprise Information Management, 18(2), 195-210.

Stapleton, G., \& Rezak, C. J. (2004). Change management underpins a successful ERP implementation at Marathon Oil. Journal of Organizational Excellence, 23(4), 15-22.

Sugiyono. (2014). Metode Penelitian Pendidikan Pendekatan Kuantitatif, Kualitatif, dan R\&D. Alfabeta.

Tarhini, A., Ammar, H., Tarhini, T., \& Masa'deh, R. (2015). Analysis of the critical success factors for enterprise resource planning implementation from stakeholders' perspective: A systematic review. International Business Research, 8(4), 25-40.

Themistocleous, M., Irani, Z., \& Love, P. E. D. (2002). Enterprise application integration : An emerging technology for integrating ERP and supply chains. Proceedings of the 10th European Conference on Information Systems, 1087-1096. https://aisel.aisnet.org/cgi/viewcontent.cgi?article=1089\&context=ecis2002

Ziemba, E., \& Obłąk, I. (2015). Change management in information systems projects for public organizations in Poland. Interdisciplinary Journal of Information, Knowledge, and Management, 10, 47-62. 